\title{
Albert V. Carozzi, Horace Bénédict de Saussure (1740-1799). Un pionnier des sciences de la terre
}

\section{Paola Sosso}

\section{(2) OpenEdition}

1 Journals

\section{Édition électronique}

URL : https://journals.openedition.org/studifrancesi/26417

DOI : 10.4000/studifrancesi.26417

ISSN : 2427-5856

Éditeur

Rosenberg \& Sellier

\section{Édition imprimée}

Date de publication : 1 avril 2007

Pagination : 186

ISSN : 0039-2944

\section{Référence électronique}

Paola Sosso, « Albert V. Carozzi, Horace Bénédict de Saussure (1740-1799). Un pionnier des sciences de la terre », Studi Francesi [En ligne], 151 (LI | I) | 2007, mis en ligne le 30 novembre 2015, consulté le 22 novembre 2021. URL : http://journals.openedition.org/studifrancesi/26417 ; DOI : https://doi.org/ 10.4000/studifrancesi.26417

Ce document a été généré automatiquement le 22 novembre 2021.

\section{(c)}

Studi Francesi è distribuita con Licenza Creative Commons Attribuzione - Non commerciale - Non opere derivate 4.0 Internazionale. 


\title{
Albert V. Carozzi, Horace Bénédict de Saussure (1740-1799). Un pionnier des sciences de la terre
}

\author{
Paola Sosso
}

\section{RÉFÉRENCE}

ALBERT V. CAROZZI, Horace Bénédict de Saussure (1740-1799). Un pionnier des sciences de la terre, Genève, Slatkine, 2005, pp. 431.

Cette nouvelle biographie d'Horace-Bénédict de Saussure qui fait suite aux trois biographies les plus importantes qui lui ont été consacrées depuis sa mort (J. Senebier, 1801, G. Cuvier, 1819, W. Freshfield, 1920) se base sur une source fondamentale qui avait été jusqu'ici ignorée, les Archives Saussure de la Bibliothèque de Genève. Une étrange conspiration et le comportement de l'auteur, timide et poussé par un désir de perfection, ont fait tomber rapidement dans l'oubli les Voyages dans les Alpes, son œuvre la plus importante qui parvient à des conclusions intéressantes, même si toujours partielles et renvoyées d'un volume à l'autre, sur les refoulements horizontaux dans la formation des grandes chaînes de montagnes; en effet de Saussure pensait garder toute sa découverte secrète jusqu'à la publication de sa «Théorie de la Terre», prévue pour la fin de sa vie et qui n'a jamais été rédigée. L'auteur de ce volume vise à réhabiliter la personne de Saussure, objet d'un mythe folklorique engendré par son ascension du Mont Blanc en 1787, en mettant l'accent sur sa réelle contribution géologique dans le contexte historique, scientifique et politique de son siècle. Cette biographie, riche et détaillée, se divise en une succession de phases désignées «objectifs» et peut être lue suivant trois trajectoires parallèles: le narratif biographique principal, formulé comme un agenda, les manuscrits, indiqués entre parenthèses, outil de recherche pour qui voudrait se plonger dans une étude savante, et les références modernes sur l'œuvre de de Saussure, données en fin de volume et organisées en ordre alphabétique à l'intérieur de chaque chapitre. A signaler encore les nombreuses images (gravures, schémas, 
reproductions de manuscrits, brouillons...) dont on trouve la liste dans l'«Annexe 1» et les lettres de de Saussure à sa femme (déjà publiées en 1937 par Emile Gaillard et Henri F. Montagnier) recueillies dans l'«Annexe 2», suivies de l'«Index des noms de lieux et des noms propres». 